\title{
Effect of Maillard Reaction Products (MRP) on Chlorophyll Stability in Green Peas
}

\section{Ranganathan Kumar, Ramalingam Rajamanickam, Shanmugam Nadanasabapathi}

Food Engineering \& Packaging, Defence Food Research Laboratory, Mysore, India.

Email: *kumardfrl@gmail.com

Received October $6^{\text {th }}, 2012$; revised January $1^{\text {st }}, 2013$; accepted January $8^{\text {th }}, 2013$

Copyright @ 2013 Ranganathan Kumar et al. This is an open access article distributed under the Creative Commons Attribution License, which permits unrestricted use, distribution, and reproduction in any medium, provided the original work is properly cited.

\begin{abstract}
Maillard Reaction Products (MRP) was prepared from glucose and glysine heated at $90^{\circ} \mathrm{C}$ in air circulating oven for 12 hours. The effect of MRP on chlorophyll stability in green peas was investigated. The addition of Maillard Reaction Products (MRP) decreased the loss of chlorophyll a, chlorophyll b and total chlorophyll. The conversion of pheophytin and pyropheophytin was also reduced by the addition of MRP.
\end{abstract}

Keywords: Colour; Chlorophyll; Maillard Reaction Products (MRP); Heat Treatment

\section{Introduction}

Colour is a major quality attribute of food products. The sensory perception of food is determined by visual perception and it plays an important role in acceptability of foods. One of the most important colour factors is the presence of green chlorophyll pigments presented in processed foods. Due to various processing/heat treatments involved in food preparation and processing, chlorophyll pigments tend to undergo drastic irreversible changes. The most common alteration occurs in green vegetables in the conversion of chlorophylls to pheophytins, causing a drastic color change from bright green to olive brown. Chlorophyll retention has been used as a measure of quality in green vegetables. Chlorophylls are susceptible to many chemical or enzymatic degradation reactions. The simultaneous actions of enzymes, weak acids, oxygen, light and heat can lead to the formation of a large number of products. Major chemical degradation routes are associated with pheophytinization, epimerization and pyrols [1]. The conversion is enhanced by extended heat treatment and is dependent upon the number of acid moiety formed during the processing and storage. Studies have indicated that during blanching, heat treatment induces the formation of the $\mathrm{C}-10$ epimers producing chlorophylls which are converted into pheophytins [2] and pheophytin epimers. Various attempts have been made to minimize the loss of chlorophylls during processing by minimizing heat exposure through high tempe-

*Corresponding author. rature short term (HTST) process or combination of short time processing with $\mathrm{pH}$ adjustments. Although most of these methods have proved to be useful in retaining chlorophyll pigments immediately after processing, the retained chlorophyll is still found to degrade rapidly during storage.

The Maillard Reaction Products (MRPS) play an important role in food processing. Maillard reaction (MR) is a very complex reaction between carbonyls and amines. It occurs spontaneously during food processing and storage, mainly by the reaction between reducing sugars and amino groups of proteins [3]. Maillard Reaction usually produces a wide range of products with odours and colours, antioxidants, antiallergenic, antimicrobial and cytotoxic properties [4,5]. The researcher [6] studied the antioxidative effect of some MRPs on lipid oxidation and it was found to slow down the formation of rancid flavour in food. The antioxidative effect of maillard reaction volatile products was developed by heated glucose-glycine mixture. The free radical scavenging activity of Maillard Reaction Products was produced by heating glucose, or lactose with lysine, alanine or glycine [7]. Antioxidant activity of water soluble Maillard Reaction Products was studied [8]. The antioxidant properties [9] of Maillard Reaction Products were obtained by gamma-irradiation of whey proteins. Few reports are available in the influence of MRPs formed in food on microorganisms. The activity of MRPs against food poisoning microorganisms includes Staphylococcus aureus, Listeria monocytogens, Salmonella typhimurium and Averomonas hydrophyila 
[10]. The inhibitory effect of MRPs on protein was studied; it was found that the MRPs compound was inhibited carboxypeptidase A [11]. Author [12] observed a strong inhibitory effect of MRPs on ployphenol oxidase (PPO) and perioxidase (PO) enzymes. The inhibition of polyphenol oxidase [13] activity and copper chelating properties of model Maillard systems was studied. It was found that the inhibitory effect of MRP on activity of two copperoxidore ductasees, apple polyphenol oxidases and mushroom tyrosinases assessed by polarography showed that thiol-derived MRE were the most potent inhibitors even at very low levels in the reaction medium. In this study, the possible effect of MRPs on chlorophyll stability in foods during heat treatments is owing to the advantages of MRPs as there is no report of MRPs on chlorophyll stability. The objectives of this study were to examine effect of Maillard Reaction Products (MRP) on chlorophyll stability in green peas.

\section{Material and Methods}

\subsection{Sample Preparation and Treatment}

Freshly harvested greens peas (Pisum Sativum) was procured from the local market, the pods were hand peeled immediately prior to the experiments. To study the effects of MRP's on chlorophyll stability, the following treatments viz, Control (T1), blanching of raw green peas for 5 minutes (open boiling) (T2), Blanching + chlorophyll fixation (T3), MRP + Blanching (T4).

\subsection{Estimation of Chlorophyll, Pheophytin and Pyropheophytin}

The sample (green peas) was extracted by blending a suitable weight in such volume of acetone that the equilibrium concentration was about $80 \%$. The pigments were then transferred to diethyl ether and the absorbance was measured at 660 and $642 \mathrm{~nm}$ and the respective absorption maxima of chlorophyll a and chlorophyll $b$ for the determination of, Pheophytin and pyropheophytin, by addition of one drop of concentrated hydrochloric acid to 25 to $50 \mathrm{ml}$ of diethyl ether solution to convert chlorophyll to pheophytin and pyropheophytin respectively. Granular anhydrous sodium sulphate was also added, to clarify and dry the solution. The ether solution was allowed to store for 2 hours in dark at room temperature. Its absorbance was then measured at 665.5 and $653 \mathrm{~nm}$ the respective absorption maxima of pheophytin a and pheophytin b [14]. All the absorbance measurements were conducted in UV-visible spectrophotometer.

\subsection{Preparation of Maillard Reaction Products}

Glucose and glysine (AR grade) were dissolved in water to obtain a $1.71 \mathrm{~m}$ glucose and $2.05 \mathrm{~m}$ glysine solution. The initial $\mathrm{pH}$ of the aqueous solution was adjusted to 6.0.
Aliquots of solution were placed in vials that were sealed and heated at $90^{\circ} \mathrm{C}$ in air circulating oven for 12 hours. The MRP content was obtained as the difference between the content of glucose and glycine before and after heating.

The template is used to format your paper and style the text. All margins, column widths, line spaces, and text fonts are prescribed; please do not alter them. You may note peculiarities. For example, the head margin in this template measures proportionately more than is customary. This measurement and others are deliberate, using specifications that anticipate your paper as one part of the entire proceedings, and not as an independent document. Please do not revise any of the current designations.

\subsection{Statistical Analysis}

The samples were analysed triplicate and data obtained were analysed statistically to find out Mean and standard deviations.

\section{Results and Discussion}

\subsection{Changes in Chlorophyll Content}

The effect of heat treatment and addition of MRP on the stability of chlorophyll in green peas has been shown in Figure 1 and Table 1. The initial chlorophyll content of

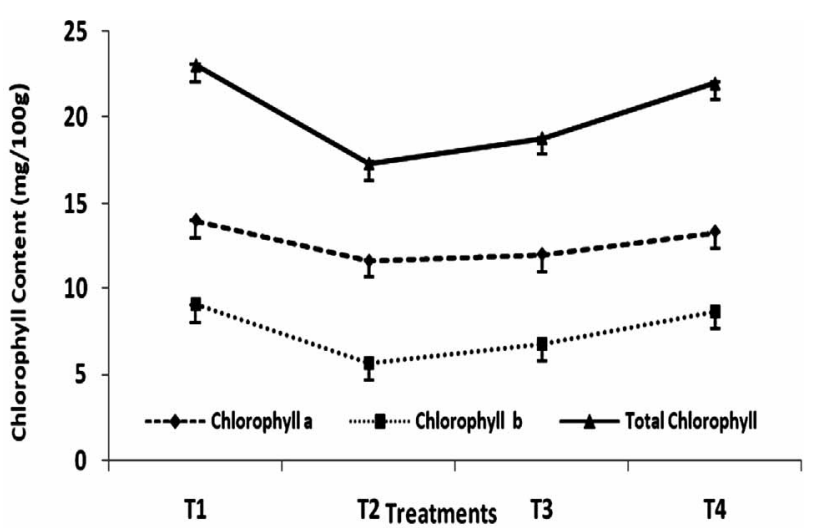

Figure 1. Change in chlorophyll content (mg/100g) of Green Peas (T1-Fresh Peas; T2 Blanching; T3 Blanching + chlorophyll fixation; T4 MRP + Blanching)

Table 1. Change in chlorophyll content $(\mathrm{mg} / 100 \mathrm{~g})$ of Green Peas (T1-Fresh Peas; T2 Blanching; T3 Blanching + chlorophyll fixation; T4 MRP + Blanching) Mean \pm SD.

\begin{tabular}{cccc}
\hline Treatments & Chlorophyll a & Chlorophyll b & $\begin{array}{c}\text { Total } \\
\text { Chlorophyll }\end{array}$ \\
\hline T1 & $14.01 \pm 0.005$ & $9.06 \pm 0.012$ & $23.06 \pm 0.015$ \\
T2 & $11.67 \pm 0.021$ & $5.68 \pm 0.005$ & $17.35 \pm 0.100$ \\
T3 & $12.05 \pm 0.020$ & $6.78 \pm 0.005$ & $18.83 \pm 0.011$ \\
T4 & $13.36 \pm 0.012$ & $8.66 \pm 0.015$ & $22.01 \pm 0.020$ \\
\hline
\end{tabular}


green peas was $23.06 \mathrm{mg} / 100 \mathrm{~g}$ has been found to reduce to $17.35 \mathrm{mg} / 100 \mathrm{~g}$ due to blanching. However, the addition of MRP at the concentration level of $1 \%(\mathrm{v} / \mathrm{w})$ has been found to have a significant effect on discoloration of chlorophyll content of green peas. Because, although the sample was subjected to heat treatment as in the case of treatment (T2), the final concentration of chlorophyll in all samples was $22.01 \mathrm{mg} / 100 \mathrm{~g}$ addition of $1 \%(\mathrm{v} / \mathrm{w})$ maillard reaction products of sample had significant effect on chlorophyll retention in green peas. Whereas the samples without MRP treatment had shown that the loss of chlorophyll pigment was maximum. The loss of chlorophyll can be due to the formation of the C-10 epimers producing Chlorophylls $a^{1}$ and $b^{1}$. Heat induced loss of green colour is a consequence [15] of both chlorophyll a and $b$ degradation. In the present study, the effect of MRP on chlorophyll stability is more when compared to the stability of chlorophyll II b. formation of Zinc-chlorophyll derivative complexes in thermally processed green pears was studied [16]. The zinc ion reactions with chlorophylls lead to the formation of zinc chlorophyll complex, Zn pheophytin a and a' compounds contributing to the green colour of thermally processed green peas.

\subsection{Changes in Pheophytin Content of Green Peas}

The effect of heat treatment and addition of MRP on the stability of phepphytin in green peas has been shown in Figure 2 and Table 2. Author [17] reported that chlorophyllb degraded at a rate approximately 25\% - 40\%

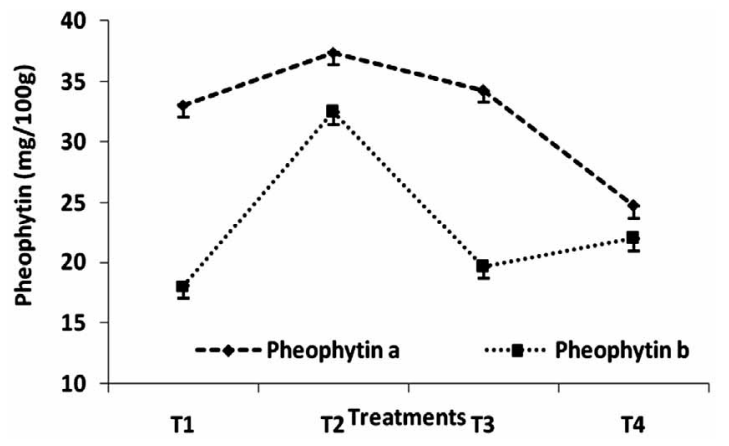

Figure 2. Change in pheophytin content (mg/100g) of Green Peas (T1-Fresh Peas; T2 Blanching; T3 Blanching + chlorophyll fixation; T4 MRP + Blanching).

Table 2. Change in pheophytin content (mg/100g) of Green Peas (T1-Fresh Peas; T2 Blanching; T3 Blanching + chlorophyll fixation; T4 MRP + Blanching) Mean \pm SD.

\begin{tabular}{ccc}
\hline Treatments & Pheophytin a & Pheophytin b \\
\hline T1 & $33.08 \pm 0.015$ & $18.02 \pm 0.020$ \\
T2 & $37.39 \pm 0.005$ & $32.48 \pm 0.01$ \\
T3 & $34.25 \pm 0.015$ & $19.65 \pm 0.020$ \\
T4 & $24.77 \pm 0.025$ & $22.01 \pm 0.015$ \\
\hline
\end{tabular}

faster that pheophytin a depending on the temperature. To estimate the effect of MRP chlorophyll conversion, the conversion of chlorophyll a to pheophytin a is minimum when compared to the conversion of chlorophyll $b$ to pheophytin b result clearly indicates that the effect to MRP is maximum in stabilizing chlorophyll a content that chlorophyll b. Generally the total destruction of chlorophylls results in the formation of phoeophytins and pyropheophytins. pH of spinach product decreases [18] with increasing heat treatment during pheophytinisation. The extent of conversion of pheophytins to pyropheophytins is related to the severity of heat treatment. In this study, it clearly indicates that at all levels the MRP plays an important role in retention of chlorophyll content.

\subsection{Changes in Pyropheophytin Content of Green Peas}

The effect of heat treatment and addition of MRP on the stability of pyropheophytin in green peas has been shown in Figure $\mathbf{3}$ and Table 3. The dependence of pheophytin conversion in an acid medium and/or heat has led many investigation of $\mathrm{pH}$ control to preserve the typical green color of chlorophyll, or minimize heat exposure by applying high temperature, short time processing or combining high temperature and time with $\mathrm{pH}$ adjustments, [19] observed greater stability of chlorophyll colour in blanched spinach puree when surfactants were added.

Enzymes systems particularly, oxidizing enzymes,

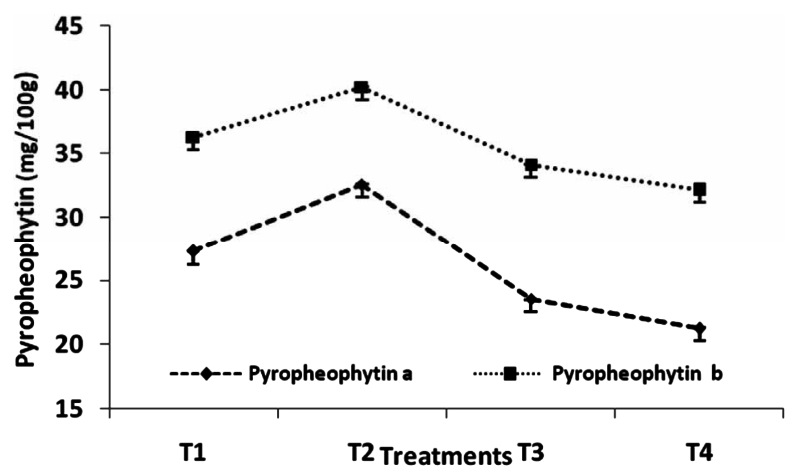

Figure 3. Change in pyropheophytin content (mg/100g) of Green Peas (T1-Fresh Peas; T2 Blanching; T3 Blanching + chlorophyll fixation; T4 MRP + Blanching).

Table 3. Change in pyropheophytin content $(\mathrm{mg} / \mathbf{1 0 0 g})$ of Green Peas (T1-Fresh Peas; T2 Blanching; T3 Blanching + chlorophyll fixation; T4 MRP + Blanching) Mean \pm SD.

\begin{tabular}{ccc}
\hline Treatments & Pyropheophytin a & Pyropheophytin b \\
\hline T1 & $27.32 \pm 0.011$ & $36.28 \pm 0.015$ \\
T2 & $32.62 \pm 0.025$ & $40.21 \pm 0.030$ \\
T3 & $23.54 \pm 0.005$ & $34.12 \pm 0.025$ \\
T4 & $21.26 \pm 0.032$ & $32.16 \pm 0.015$ \\
\hline
\end{tabular}


have been implicated as factors in chlorophyll degradation. They have reported that the loss of chlorophyll is frozen peas associate with lipoxygenase activity and fat peroxidation. Author [20] reported chlorophyll blanching in a mixture of fatty acid lipoxygenate and legume seed extract. Oxygen was required for the reaction to proceed and prooxidants inhibited the rate. The exact mechanism of MRP on chlorophyll stability may be attributed to the presence of furfural of 5-HMF. The $\mathrm{pH}[6]$ range (6 - 9) gave the strictest antioxidative effect of MRP's. Further more there is possibility that the colour stability effect on MRP is due to free radicals formed during the heating of sugars and amines [21].

\section{Conclusion}

During heat treatment, chlorophyll degrades to pheophytin, which in turn decomposes to other degradation products. Both chlorophyll and pheophytin conversion can be minimized by the addition of maillard reaction products to improve the colour stability. The present study clearly shows the advantage of using MRP on chlorophyll stabilization and retention in green peas.

\section{REFERENCES}

[1] M. L. Gunawan and S. A. Barringer, "Green Colour Degradation of Broccoli Due to Acid and Microbial Growth," Journal of Food Processing and Preservation, Vol. 24, No. 3, 2000, pp. 253-263. doi:10.1111/j.1745-4549.2000.tb00417.x

[2] G. L. Robertson, "Changes in the Chlorophyll and Pheophytin Concentrations of Kiwifruit during Processing and Storage," Food Chemistry, Vol. 17, No. 1, 1985, p. 25. doi:10.1016/0308-8146(85)90089-5

[3] S. C. Liu, D. J. Yang, S. Y. Jin, C. H. Hsu and S. C. Chen, "Kinetics of Colour Development, pH, Decreasing and Antioxidative Activity Reduction of Maillard Reaction in Galactose/Glycine Model System,” Food Chemistry, Vol. 108, No. 2, 2008, pp. 533-541. doi:10.1016/j.foodchem.2007.11.006

[4] M. Plavsic, B. Cosovic and C. Leee, "Copper Complexing Properties of Melanoidins and Marine Humic Material," Material Science of the Total Environmental, Vol. 366, No. 1, 2006, pp. 310-319. doi:10.1016/j.scitotenv.2005.07.011

[5] J. A. Rufian-Henares and F. J. Morales, “A New Application of a Commercial Microtiter Plate Based Assay for Assessing the Antimicrobial Activity of Maillard Reaction Products," Food Research International, Vol. 39, No. 1, 2006, pp. 33-39. doi:10.1016/j.foodres.2005.06.002

[6] H. Lingnert and C. E. Erikson, "Antioxidative Effect of Maillard Reaction Products,” Food and Nutritional Science, Vol. 5, 1981, pp. 453-458.

[7] F. J. Morales and S. Jimmenez-Perz, "Free Radical Scavenging Capacity of Maillard Reaction Products as Related to Colour and Fluorescence,” Food Chemistry, Vol. 72, No. 1, 2001, pp. 119-125. doi:10.1016/S0308-8146(00)00239-9

[8] Y. Yilmaz and R. Toledo, “Antioxidant Activity of Water Soluble Maillard Reaction Products," Food Chemistry, Vol. 93, No. 2, 2005, pp. 273-278.

doi:10.1016/j.foodchem.2004.09.043

[9] S. P. Chawla, R. Chander and A. Sharma, "Antioxidant Properties of Maillard Reaction Products Obtained by Gamma Irradiation of Whet Proteins," Food Chemistry, Vol. 116, No. 1, 2009, pp. 122-128. doi:10.1016/j.foodchem.2009.01.097

[10] M. Stecchini, P. Giavedoni and C. R. Lerici, “Antimicrobial Activity of Maillard Reaction Products against Aeromonas Hydophila,” Italian Journal of Food Science, Vol. 5, No. 2, 1993, pp. 147-150.

[11] R. E. Oste, R. Miller, H. Sjostrom and O. Norem, "Effect of Maillard Reaction Products on Protein Digestion," Journal of Agricultural Chemistry, Vol. 35, No. 6, 1987, pp. 938-942. doi:10.1021/jf00078a020

[12] M. C. Nicoli, B. Elizalde and C.R. Lerici, "Effect of Sugars and Maillard Reaction Products on Polyphenol Oxidase and Peroxidase Activity in Food," Journal of Food Biochemisry, Vol. 15, No. 3, 1991, pp. 169-184. doi:10.1111/j.1745-4514.1991.tb00153.X

[13] M. N. Maillard, C. Billand, Y. N. Chow, C. Ordonald and J. Nicolar, "Free Radical Scavenging Inhibition of Polyphenol Oxidase Activity and Copper Chelating Properties of Model Maillard System,” LWT-Food Science and Technology, Vol. 40, No. 8, 2007, pp. 1434-1444.

[14] L. P. Veron, "Spectrophotometric Determination of Chlorophylls and Pheophytins in Plant Extracts," Analytical Chemistry, Vol. 32, No. 9, 1960, pp. 1144-1150. doi:10.1021/ac60165a029

[15] S. S. Teng and B. H. Chen, "Formation of Pyrochlrophylls and Their Derivatives in Spinach Leaves during Heating," Food Chemistry, Vol. 65, No. 3, 1999, pp. 367373. doi:10.1016/S0308-8146(98)00237-4

[16] T. Ngo and Y. Zhao, "Formation of Zinc Chlorophyll Derivative Complexes in Thermally Processed Pears," Journal of Food Science, Vol. 72, No. 7, 2007, pp. 397-404. doi:10.1111/j.1750-3841.2007.00465.x

[17] S. J. Schwartz and T. V. Lorenzo, "Chlorophylls in Foods," CRC Critical Reviews in Food Science and $\mathrm{Nu}$ trition, Vol. 29, No. 1, 1990, pp. 1-17. doi:10.1080/10408399009527511

[18] S. J. Schwartz and T. V. Lorenzo, "Chlorophyll Stability during Continuous Aseptic Processing and Storage," Journal of Food Science, Vol. 56, No. 4, 1991, pp. 13031306. doi:10.1111/j.1365-2621.1991.tb14641.x

[19] F. M. Clydesdale and F. J. Francis, “Chlorophyll Changes Aseptically Processed Spinach as Influenced by Enzyme Conversion and Heat Treatment," Journal of Food Technology, Vol. 22, 1974, pp. 793-796.

[20] M. A. Hudson, V. J. Sharples and M. E. Gregory, “Quality of Home Frozen Vegetables II. Effect of Branching and/or Cooling in Various Solutions on Conversion of Chlorophyll,” Journal of Food Technology, Vol. 9, 1974, 
pp. 105-108. doi:10.1111/j.1365-2621.1974.tb01750.x

[21] S. H. Ashoor and J. B. Zent, "The Maillard Browning of Common Amino Acids and Sugars," Journal of Food Sci- ence, Vol. 49, No. 4, 1984, pp. 1206-1207. doi:10.1111/j.1365-2621.1984.tb10432.x 